\title{
Formation of independence motivation based on rehabilitation work with children with cochlear implants
}

\author{
Rakhimova Khurshidahon Sodiqovna ${ }^{1}$, Azimova Zulfiya ${ }^{2}$ \\ ${ }^{1}$ KSPI named after Muqimi teacher of the Defectology department \\ ${ }^{2}$ KSPI named after Muqimi Student of the Defectology 4 courses
}

\begin{abstract}
This article lists the modern methods and their possibilities in restoring hearing abilities in children with hearing problems. Effective factors in preparing children with cochlear implants for independent life are highlighted.
\end{abstract}

Keywords: Deafness, hearing impaired child, hearing, auditory perception, method, independent activity, effective factors, cochlear implant.

\section{INTRODUCTION}

Prosthetics of hearing, timely correction of impaired hearing functions in deaf and hard of hearing children, pave the way for the active formation of auditory perception from the earliest stages. As a result, children start developing speech activity and based on that their intellectual activity. Adults who have used cochlear implants in practice claim that using this device makes sound and speech sound relatively natural, expands the ability to find different sound sources, and reduces fatigue when paying too much attention to hearing. Children with hearing impairments may need a different type of hearing aid if soundenhancing devices are not effective when they are 2 to 3 years old. As a means of effectively restoring such hearing, a cochlear implant is surgically inserted into the child. The earlier the child is operated on, the sooner the problems in his speech development will be eliminated.

Cochlear implantation - allows children with hearing problems to hear and distinguish all the sounds around them, to speak, to hear their own speech. That is, it serves as a means of ensuring social adaptation by bringing it into the world of the listener. When a cochlear implant is placed, the child will be able to distinguish between speaking and non-speaking sounds. However, in children with cochlear implants, the expected result will not be achieved if rehabilitation is not performed before and after surgery. That is, children do not perceive the external world through the sense of hearing, and as a result do not distinguish when they hear the speech of others. Children with cochlear implants should receive targeted deaf pedagogy for some time. The effectiveness of deaf pedagogy depends on the direct involvement of parents in this process. This requires regular verbal communication with the child with a cochlear implant in natural conditions in the family, especially during play. Otherwise, the work of the deaf pedagogue will lose its effectiveness. It is known that after cochlear implantation we considered it expedient to divide the work of hearing and speech rehabilitation with children into the following periods:

1. Adaptation period. This period lasts from 1 to 3 months, depending on the general condition of the child. In this case, the implant adapts to the child's body and vice versa the child's body to the foreign element in the body. In practice, adverse effects on the adaptation of the child's body to the implant can also be observed. In such cases, medical rehabilitation procedures are carried out on the basis of general cooperation of surgeons, pediatricians, therapists.

As well as that, this period includes the following activities:

1. Psychological preparation of mother and child for the correctional and pedagogical process.

2. Preparing the child to turn on the speech processor (conditioned motion response to sounds, explaining the presence or absence of sound, limiting the volume to be heard). In addition, the preoperative period will continue at this stage (counseling for parents, one-on-one sessions with a deaf educator and psychologist, recommendations on hearing aids, personal planning for hearing and speech rehabilitation at home and in the family).

Important tasks at this stage are the types of work that connect the speech processor before and after it is activated. That is, the work of teaching to distinguish between non-verbal and verbal sounds will continue under the supervision of a specialist.

2. Start period. That is, in the initial stage, the electrode part of the cochlear implantation is activated by a specialist of the deaf center in a centralized manner using a special device. This process involves 
diamically controlling the child's perception and response to the outside world. In the first phase of the start period, a general adjustment level is set for all children. The content of the work of a deaf pedagogue is as follows:

1) Work is carried out on the speech sound. This includes responding to different sounds, attracting attention, arousing interest in the surrounding sounds, distinguishing between non-verbal and spoken sounds, searching for and identifying the source of sound;

2) generalization of auditory imagery, images (spoon, knife, spoon, pot - sounds in the kitchen; voices of parents, brothers, sisters - the voices of family members; the sounds of cows, dogs, chickens, sheep the sounds of pets);

3) to teach parents to develop the child's hearing in the context of domestic communication. Speech development involves the development of sounds and the pronunciation of sounds:

- development of speech breathing;

- achieving continuity of exhalation;

- airflow diversion;

Working on sound:

- sound-calling;

- hearing control;

- control the volume, pitch, timbre of the sound;

The main period includes three major types of work:

1. Develop listening comprehension.

2. Develop language, speech, and as well as listening comprehension of one' own speech.

3. Develop listening comprehension, comprehension of complex texts.

We found that the following factors influence the setting of CI in order to restore hearing perception in children with hearing impairment:

1. Absence of serious problems in the general physiological condition of the child: anemia, complications of acute respiratory disease, drug allergy.

2. In the case of hearing aids: preservation of auditory nerve fibers, ear supraspinatus, absence of retrocochlear pathology, smoothing of the ear mucosa.

3. Related to brain activity: the absence of injuries to the skull, infectious diseases, organic disorders.

4. In the psychological state of the child: lack of serious problems in communicating with relatives, adults, professionals.

5. Attention to the child in the family: understanding the importance of pre-surgery, during the surgery, and post-surgery process.

\section{Factors influencing the effective organization of correctional and pedagogical work after cochlear implant placement:}

1. The presence of educational environment in the family. The availability of special corner for lessons, toys, provision of didactic aids, warm attitude of parents and relatives to the child, adherence to articulatory skills in speech, prevention of unpleasant sounds, timely support of each result of the child, patience in the child's adaptation to cochlear implantation, preparing himself and others to be careful with the external part of the cochlear implant standing on the child's head.

Organization of specialist activities. This process includes:

-targeted search for a specialist;

- conclusion of a fixed-term contract;

-planning together with a specialist;

-receive advice from a specialist on training topics;

- timely adjustment of the cochlear implant;

- recording the dynamic changes in the child;

2. Effective communication. Creating a variety of speaking situations, organizing question-andanswer sessions, helping to build communication with peers and adults.

3. Establishing cooperation. Establishing a partnership between a psychologist, a therapist, a psychiatrist, a preschool organization, a deaf educator and families.

In the works of Uzbek scientists U. Fayziyeva, F. Qodirova, D. Nazarova and others, the direct impact of difficulties in hearing or loss of hearing on the insufficient formation of speech abilities in children has been studied on a scientific and practical basis. From this we can draw the following conclusion: 
1. A deaf child does not understand the speech spoken to him because he has not heard it.

2. A deaf child achieves the ability to understand speech by himself and others through special correctional approaches or hearing aids.

3. Corrective-pedagogical work with deaf children after speech formation and cochlear implant placement is radically different from deaf pedagogical work with children with cochlear implantation without speech formation.

4. Depending on the onset of deafness and the timing of cochlear implant placement, the content of postoperative work is developed in a specific way.

The main direction of correctional-pedagogical, developmental work carried out after cochlear implantation is to teach communication, which has a positive impact on the speech development of deaf children. In our opinion, as a final result of cochlear implantation, we can see that the life activity of implanted children is increased, their social adaptation is increased, auditory perception is improved, oral speech is formed as the main means of knowledge acquisition and communication with hearing people. Rehabilitation of children after cochlear implantation is a long, planned process. The first 2 years are of particular importance in this regard. It is during this period that otorhinolaryngologists provide medical-psychological-pedagogical support to each child, that is, the planned connection and adjustment of the speech processor, pedagogical examination, correctional-developmental training, the advice of specialists in various fields.

In conclusion, cochlear implantation is recognized today as an effective tool in the pedagogical rehabilitation of children with hearing impairment.

According to the theories proposed by A.N. Belokon N.A. Dayxes, A.V. Pashkov, the success of interventions after cochlear implant placement depends on medical, psychological, pedagogical and social factors: The course of the surgical procedure, the adjustment of the speech processor to the child's hearing capabilities, taking into account the individual characteristics of the implanted child, the awareness of parents about the work with children with cochlear implants.

\section{List of used literature}

1. Koroleva I.V. Hearing and speech rehabilitation of deaf children with cochlear implants. - SPb., 2005.

2. Koroleva I.V. Prediction of the effectiveness of hearing-speech rehabilitation after cochlear implantation in young children // Defectology, 2002.

3. Fayzieva U, D.Nazarova, F.Qodirova. T., Deaf pedagogy (textbook) "Sano standart" publishing house. 2012.

4. Raximova X. Isoqjonova D. Factors of development of cochlear implantation in Uzbekistan // "Child and Time" 2019, issue 4. 35-36 b.4.

5. www.cochlear.com 